\title{
A NECESSÁRIA SUPERAÇÃO DO MODELO REPRESENTATIVO HEGEMÔNICO NA CONSTRUÇẨO DO EMPODERAMENTO SOCIAL LOCAL
}

\author{
Ricardo Hermany ${ }^{1}$ \\ Dartagnan Limberger Costa
}

\section{RESUMO}

A ideia democrática incorpora a superação da visão legalista ou meramente representativa dos anseios sociais. Os filtros utilizados pelos representantes do povo denotam certa mudança nos interesses sociais, sofrendo a interferências de outros atores sociais, como por exemplo o Mercado, na real intenção e direcionamento das vontades populares na consecução de um Estado Democrático de Direito. Nesse sentido, é imperioso destacar a necessária superação da visão representativa em detrimento da hermenêutica ampla que denota a emanação do poder pelo próprio povo, o que abre o debate sobre a criação de espaços públicos dialógicos na consecução dos interesses sociais. São esses espaços públicos que permitirão que se crie e se retro-alimente o capital social nas comunidades, gerando o devido empoderamento social, o qual, é o único mecanismo possível de tornar a vontade popular realmente passível de internalização nas demandas públicas e sociais.

Palavras-Chave: Capital social. Empoderamento social. Município Representação e gestão compartida.

\section{INTRODUÇÃO}

Atualmente não são poucas as vozes, tanto na seara política como acadêmica, que procuram dar foco ao que contemporaneamente denomina-se de empowerment. E através desse ideário que se traz ao debate acadêmico a viabilidade, através de ações dialógicas, de vislumbrarmos uma maior influência dos interesses da sociedade, já vista como sujeito ativo, em face do Estado e do Mercado.

Mas esse ideário só é capaz de se desenvolver se tivermos algumas premissas em proeminência, afinal, uma sociedade civil ativa e empoderada, só será capaz de fazer frente aos demais atores sociais se possuir, no seu cerne, um ambiente democrático capaz de fomentar a participação. Tal participação deve provir do próprio interesse dos cidadãos, de forma organizada, dentro da esfera pública não estatal.

A democracia é o único ambiente capaz de ensejar tal finalidade, eis que viabiliza uma relação de diálogo entre os membros de uma comunidade, com fins de organização não-coatada. Justamente essa possibilidade que abre margem para formação das associações e demais movimentos que formam a sociedade civil, permitindo que a mesma se expresse em favor ou desfavor dos outros sujeitos sociais, tais como o Estado e o Mercado. 
A formação de capital social gerado por essa união de pessoas, enseja o crescimento e amadurecimento dos debates na esfera pública, ampliando as possibilidades de crescimento da comunidade frente ao ideário neoliberal que constringe as relações humanas que destoam da necessidade social, o que, de forma peremptória, fomentará o que se denomina de empoderamento.

A sociedade civil ao se empoderar, se torna sujeita ativa, consciente de suas responsabilidades e de suas influências, vislumbrando maiores resultados, decorrentes de sua organização associativa, no que lhe convém.

Diante disso, passaremos a analisar os temas delineados e fazer uma exposição crítica da necessidade dessa sociedade como núcleo resguardativo dos interesses sociais em função dos interesses do Estado e do Mercado.

\section{A NECESSÁRIA SUPERAÇÃO DO MODELO REPRESENTATIVO POLÍTICO: A DEMOCRACIA PARTICIPATIVA COMO INSTRUMENTO DE INCLUSÃO SOCIAL}

A necessidade do debate sobre democracia direta e indireta encontra-se calcado na busca por maior efetividade dos interesses da sociedade em detrimento dos interesses, muitas vezes, obscuros do Estado e os mercadológicos ${ }^{3}$. 0 cerne do ideário participativo, que fomenta o empoderamento, é calcado num viés ampliativo entre a sistemática da democracia direta e indireta, repercutindo, na análise das mesmas, em buscar uma miscigenação, capaz de viabilizar a efetivação da cidadania ativa.

A democracia direta tem como seu autor de maior renome o filósofo Rousseau, o qual empregou o termo como forma de caracterizar o que, supostamente, existia em Atenas, por volta dos séculos V e IV a. C., em que, haveria a possibilidade de votações diretas nos assuntos que interessavam à polis. ${ }^{4}$ Rousseau em sua obra " $O$ Contrato Social' inicia delimitando que 'O homem nasce livre. E por toda parte encontra-se a ferros." ${ }^{, 5}$ Vindo, posteriormente a tecer uma dura crítica ao sistema representativo, onde delimita que:

\footnotetext{
Os deputados do povo não são, nem podem ser seus representantes; não passam de comissários seus, nada podendo concluir definitivamente. É nula toda lei que o povo diretamente não ratificar; em absoluto, não é lei. $O$ povo inglês pensa ser livre e muito se engana, pois só o é durante a eleição dos membros do parlamento; uma vez estes eleitos, ele é escravo, não é nada. Durante os breves momentos de sua liberdade, o uso, que dela faz, mostra que merece perdê-la. ${ }^{6}$
}

Rousseau é enfático ao desprezar a sistemática representativa, demonstrando sua notória visão de que a soberania popular provém do povo e nele deve permanecer, mesmo acreditando, em seu ímpeto, que a democracia direta em grandes ambientes era inviável. Importante ressaltar que, conforme Pateman ${ }^{7}$, Rousseau sai do foco da democracia de massa para interagir no psicológico do indivíduo no que refere a suas posições dentro do grupo. Ensina Pateman: 
do que um complemento protetor de uma série de arranjos institucionais: ela também provoca um efeito psicológico sobre os que participam, assegurando uma inter-relação contínua entre o funcionamento das instituições $e$ as qualidades e atitudes psicológicas dos indivíduos que interagem dentro delas. ${ }^{8}$

Ainda delimita a autora que Rousseau considerava que a situação ideal para interação decisional, além dos pressupostos da liberdade, igualdade e independência econômica, ou seja, num pressuposto existencial mínimo para que as decisões não fossem "compradas", houvesse uma relação de interdependência, onde nenhum indivíduo poderia obter o que desejava sem a cooperação dos demais.

Bobbio expõe que o próprio Rousseau era descrente de uma idéia de democracia direta na conjuntura social de seu tempo, resumindo os problemas de sua efetividade na seguinte exposição:

Rousseau entretanto também estava convencido de que "uma verdadeira democracia jamais existiu nem existirá", pois requer muitas condições difíceis de serem reunidas. Em primeiro lugar um estado muito pequeno, "no qual ao povo seja fácil reunir-se e cada cidadão possa facilmente conhecer todos os demais"; em segundo lugar, "uma grande simplicidade de costumes que impeça a multiplicação dos problemas e as discussões espinhosas"; além do mais, "uma grande igualdade de condições e fortunas"; por fim, "pouco ou nada de luxo" (donde se poderia deduzir que Rousseau, e não Marx, é o inspirador da política de "austeridade").

Nota-se que no caso brasileiro os medos de Rousseau se mostrariam substanciais na construção de uma democracia direta, afinal, nosso país é evidentemente heterogêneo, de grande extensão e muito desigual em termos econômicos e educacionais. Ao ampliarmos o debate em contraposição ao ideário de democracia direta, podemos vislumbrar a sistemática da democracia indireta, mediante a representação. Nesse sentido Bobbio é elucidativo:

A expressão "democracia representativa" significa genericamente que as deliberações coletivas, isto é, as deliberações que dizem respeito à coletividade inteira, são tomadas não diretamente por aqueles que dela fazem parte, mas por pessoas eleitas para esta finalidade. Ponto e basta. ${ }^{10}$

Já Schumpeter, ao instigar o debate delimita o seguinte questionamento: "de que maneira será tecnicamente possível ao povo governar?"11 ao se referir à democracia direta. $E$, na dificuldade de viabilidade prática dessa sistemática, conforme até mesmo elencado por Bobbio $^{12}$, crê o autor que deveria haver uma substituição do "governo do povo" pelo "governo aprovado pelo povo". Schumpeter ao delimitar tal prerrogativa argumenta:

Há muitas razões para se adotar essa solução. Numerosas afirmações que fazemos usualmente a propósito da democracia se aplicariam a todos os governos que contam com a lealdade da grande maioria do povo ou, melhor ainda, da grande maioria de todas as classes do povo. Isso se aplica particularmente às virtudes usualmente vinculadas ao método democrático: a dignidade humana, a satisfação de ver que, de maneira geral, os assuntos políticos se desenrolam de acordo com as expectativas da pessoa, a coordenação da política com a opinião pública, a confiança e a cooperação do cidadão com o governo, a dependência deste último do respeito e do 
apoio do homem das ruas - tudo isso e muito mais, que tantos de nós consideram a própria essência da democracia, é satisfatoriamente abrangido pela idéia do governo aprovada pelo povo. ${ }^{13}$

Mas tal solução ainda é frágil, merecendo ser melhor explanada em face de diversos exemplos que tal prerrogativa poderia causar. $O$ próprio autor delimita que, por exemplo, um simples líder carismático poderia instaurar uma tirania com o consenso popular através do voto. Exemplo contemporâneo foi a notória utilização dos referendos na Alemanha para solidificar as idéias nazistas durante o período genocida $^{14}$.

Centrado na realidade fática e nas impossibilidades de premissas intrínsecas ao ser humano, Schumpeter delimitou que o método democrático seria um "arranjo institucional para se chegar a decisões políticas, no qual os indivíduos adquirem o poder de decidir utilizando para isso uma luta competitiva pelo voto do povo,"15, respeitados, conforme Pateman, prerrogativas de liberdades civis, de opinião, de eleições livres e dos princípios que estruturam a sociedade existente. ${ }^{16}$

Mas, para além dessas delimitações, cabe reforçar o entendimento empreendido por Pateman, onde a autora é enfática ao delimitar que em qualquer que fosse o sistema adotado, as instituições deveriam ser democratizadas (Administração Pública e Mercado), afinal, seja pela participação direta ou pela indireta, o indivíduo estaria preso a delimitações que lhe impossibilitariam o seu exercício pleno participativo ${ }^{17}$. Nesse sentido se torna importante a reflexão sobre as esferas públicas não-estatais de fomentação democrática. Deve o Estado criar lócus para viabilizar a participação dos indivíduos, de forma organizada, em prol dos interesses da própria sociedade ${ }^{18}$.

No caso brasileiro, podemos notar que existe uma viabilidade de compartilhar essas duas formas de democracia na construção de uma sociedade civil mais forte e mais cidadã. Políticas públicas de inclusão social, entre as quais a Governança Solidária Local de Porto Alegre, são exemplos claros que os cidadãos podem ocupar espaços dialógicos, fora da esfera estatal, para viabilizar, de forma organizada, os seus interesses. Só que, na existência de tais espaços, surge o debate sobre algo que é fundamental para a consecução desses ideários emancipatórios, a própria concentração de capital social na determinada comunidade.

\section{PRERROGATIVAS E CONSTRUÇÕES SOBRE O EMPODERAMENTO SOCIAL LOCAL: A FOMENTAÇÃO DO CAPITAL SOCIAL COMO INSTRUMENTO DE CIDADANIA ATIVA}

Não há como desvincular a formação do capital social do sistema democrático, pois, sem democracia não há permissibilidade de formação de redes, de interação entre os agentes sociais e nem mesmo viabilidades dialógicas formativas da cidadania. A formação do capital social está intrinsecamente vinculada à formação do capital humano, a qual, muito bem delimita o professor Adriano Vasco Rodrigues, é assim sintetizada:

Sem aprendizagem não há democracia nem há cooperação. É necessário formar e informar, educando o cidadão, sensibilizando-o para os valores democráticos indispensáveis à aquisição de aptidões cooperativas, visto a 
democracia ser um regime social particular. Por isso, o campo escolar não pode ser neutro, impedindo os alunos da iniciação nos princípios democráticos, voltados para a solidariedade, a justiça, o respeito mútuo, os direitos humanos e os deveres morais e sociais. ${ }^{19}$

Nessa mesma linha seguem os ensinamentos trazidos por Schmidt ao corroborar com o ideário de que a educação é a fonte primordial de empreendimento de capital humano, ensina o autor que somente por ela, entendida como recurso indispensável para os indivíduos, que se pode "propiciar 0 incremento da produtividade dos mesmos, constitui-se elemento fundamental para 0 desenvolvimento econômico e social.". ${ }^{20}$ Nesse ponto fazemos alusão que a educação, como instrumento de capacitação e socialização dos cidadãos, perpetrada pelo Estado, deve romper o ideário de mera reprodução das relações de produção ${ }^{21}$, focando a emancipação racional do sujeito através do incremento da racionalidade crítica, capaz de pensar e se manifestar em face das relações sociais.

Sem capital humano não há como gerar capital social de qualidade. 0 termo capital social não é novo, datando de 1916, proveniente dos estudos do professor Lyda Johnson Hanifan ${ }^{22}$, o qual vislumbrou que a viabilidade de crescimento de uma comunidade, pautada dentro de um regime democrático, para se fortalecer, seria a criação de laços, ocupando-se dos interesses comuns.

Contemporaneamente o tema tomou grande monta em função de dois autores: James Coleman e Robert Putnam. James William Coleman, que traz a idéia de que, além dos capitais financeiros e humanos, a sociedade criaria vínculos que permitiriam uma maior inter-relação entre as pessoas com seu meio, entendendo que o capital social não é apenas uma entidade, mas um conjunto delas com dois traços em comum:

[...] todas elas consistem de algum aspecto das estruturas sociais, e elas facilitam certas ações de certos atores - sejam eles pessoas ou atores em agregado - dentro da estrutura. Como outras formas de capital, o capital social é produtivo, tomando possível a consecução de certos fins que na sua ausência não seriam possíveis. ${ }^{23}$ - [Tradução livre]

Mas, a notoriedade que desencadeia o tema do capital social, vislumbra-se nos escritos de Robert Putnam ${ }^{24}$, em meados do ano de 1993, em que analisou as disparidades de desenvolvimento entre o sul e o norte da Itália. Putnam analisa o processo de descentralização da Administração Pública na Itália e os pressupostos políticos, administrativos e de desenvolvimento social nas áreas norte e sul do país. Ensina a professora Maria Celina de Araújo que:

Os estudos de Putnam envolveram técnicas e metodologias variadas e cuidados sistemáticos para garantir a fidedignidade das informações. Assim, durante vinte anos analistas acompanharam 0 processo de implantação e os resultados do governo descentralizado na Itália descentralização essa que implicou a criação de vinte regiões administrativas autônomas. ${ }^{25}$

Passado esse ínterim, Putnam pôde vislumbrar que o Norte estava muito mais desenvolvido que o Sul. Ambos conseguiram avanços significativos, mas o Norte soube melhor aproveitar a descentralização desencadeada. Analisando tal prerrogativa, o autor passou a buscar a causa de tamanha disparidade. Em seu 
estudo pôde vislumbrar que o Sul permanecia com uma cultura política atrasada, baseada no clientelismo, na inépcia dos burocratas e no câncer da corrupção.

Como preleciona a autora, Putnam procurou compreender as diferenciações de desempenho institucional, muitas vezes recorrendo a outras variáveis, acabando por analisar a valorização da cultura cívica, a cultura política e as tradições existentes. Sendo assim, concluiu que o Norte teve maior desenvolvimento em decorrência dessas prerrogativas específicas. Complementam Santos Júnior, Azevedo e Queiroz Ribeiro:

No referente à cultura cívica de participação, identificamo-nos com a abordagem de Robert Putnam. No seu clássico estudo sobre a reforma institucional da Itália, o autor conclui que o contexto social está relacionado à natureza da vida cívica, que denomina de "comunidade cívica", caracterizada "por cidadãos atuantes e imbuídos de espírito público, por relações políticas igualitárias, por uma estrutura social firmada na confiança e na colaboração". Nessa abordagem, a cultura cívica é a expressão não apenas das regras de reciprocidade, mas da corporificação de sistemas de participação social, formados pelas associações da sociedade organizada, que representam uma forma de capital social. ${ }^{26}$

Sendo assim, pode-se concluir que a cultura cívica poderia, associada à confiança interpessoal, beneficiar o grupo como um todo. Daí a idéia de criação de laços horizontais nas relações humanas, fato fundamental para entender 0 viés associativista da sociedade civil e seu devido empoderamento.

Dessa forma, podemos sintetizar o significado de capital social como o conteúdo de algumas relações sociais, que vinculam atitudes de confiança com condutas de reciprocidade e de cooperação, propiciando maiores benefícios aos envolvidos, obtendo-se resultados mais eloqüentes. ${ }^{27}$

Uma sociedade civil deve ter esse requisito intrínseco para seu devido fortalecimento, pois, é justamente essa caracterização, fundada na cooperação, confiança, identidade de interesses, etc., que permite viabilizar a criação do que se denomina de unidade, mas não uma unidade manejável para fins particularistas, mas aquela construída dentro dos parâmetros constitucionais e sociais superiores de nossa nação, afinal, somente um grupo calcado nos mesmos ideais democráticos e dialógicos, é capaz de atuar firmemente em detrimento dos interesses privatísticos e clientelistas.

A partir dessa conjuntura que entendemos a possibilidade real de gerar capital social na intenção do próprio empoderamento da sociedade e da possibilidade de exercício pleno da cidadania. Sabe-se da dificuldade de vislumbrar espaços capazes de permitir que a sociedade viabilize instrumentalmente suas vontades perante o Estado e o Mercado, mas, em um sistema democrático, é o Estado que deve permitir que esses grupos possam expor seus interesses e trazerem ao debate. Nesta esteira, deve a administração pública, como preceitua Leal:

[...] criar condições à instituição de uma comunicação e linguagem decodificada e democrática, com o que permitirá a validação racional das questões normativas e operativas de suas ações - já não mais suas, mas de toda a comunidade -, isto porque, tal validez passa a ser compreendida 
como dependente de um processo intersubjetivo, regulado por razões e por posições tomadas racionalmente. ${ }^{28}$

O locus essencial para tal viabilidade consubstancia-se no ideário de esfera pública não-estatal. Ao se falar em esfera pública se deve ter em mente a proposição habermasiana no que tange à participação popular, de forma racional, na construção de prerrogativas capazes de permitir uma dialógica com vistas à consensualidade. Entende Habermas que a

[...] esfera pública constitui principalmente uma estrutura comunicacional do agir orientado pelo entendimento, a qual tem a ver com o espaço social gerado no agir comunicativo, não com as funções nem com os conteúdos da comunicação cotidiana. ${ }^{29}$

Dentro do exposto, acreditamos que temos sustentação suficiente para viabilizarmos um debate sobre a própria sociedade civil e seu devido empoderamento social na construção de uma sociedade mais ativa e participativa, até mesmo para permitir a democratização das instituições.

\section{O EMPODERAMENTO SOCIAL LOCAL: A NECESSÁRIA DEMOCRATIZAÇÃO DO ESTADO NA CONSECUÇÃO DOS PARADIGMAS DEMOCRÁTICOS DE ESTADO}

Em função da dificuldade de democratizar as instituições ${ }^{30}$ que permeiam a vida cotidiana dos cidadãos, pretende-se abrir o debate sobre a viabilidade, somando-se o ambiente democrático e o acúmulo de capital social, de expor a importância da sociedade civil organizada, entendida como sujeito social, capaz de empoderar-se para realizar pressão por seus interesses tanto contra o ente estatal como perante o mercado.

A idéia de sociedade civil não é nova, tendo sua primeira aparição no texto "Política", de Aristóteles, surgida em função da tradução da expressão "koinonia politike" para "societas civilis". Com o passar dos tempos, sua expansão conceitual teve maior foco entre os contratualistas, que procuravam uma forma de expor que a sociedade poderia se regular mediante pactos de leis, fugindo dessa forma do ideário imaginário de estado de natureza. Tal postura era essencial para justificativa de suas teorias, notando que, dessa forma, o Estado estaria ligado à própria sociedade, afinal, seria ela quem o criaria e que o regularia. ${ }^{31}$

Hobbes foi o primeiro dos contratualistas a dirimir sobre o tema, procurando justificar sua teoria no Leviatã. Rousseau e Locke ampliaram a visão de sociedade civil incluindo o ideário de propriedade. Nota-se o delimitado por Rousseau:

[...] o primeiro que, tendo cercado um terreno, atreveu-se a dizer: 'isto é meu', e encontrou pessoas simples o suficiente para acreditar nele, foi o verdadeiro fundador da sociedade civil. Quantos crimes, guerras, assassínios, quantas misérias e horrores não teria poupado ao gênero humano aquele que, arrancando as estacas ou enchendo o fosso, houvesse gritado aos seus semelhantes: 'Evitai ouvir esse impostor. Estareis perdidos se esquecerdes que os frutos são de todos e que a terra não é de ninguém. ${ }^{32}$ 
Locke, na sua obra, "O Segundo tratado sobre o governo civil e outros escritos: ensaio sobre a origem, os limites e os fins verdadeiros do governo", começa a demonstrar substancialmente o ideário individualista do homem em sociedade, notoriamente pela influência do desenvolvimento capitalista agrário de sua época.

Sem adentrarmos firmemente na análise das críticas dessa concepção, passamos de imediato ao entendimento que vislumbramos pertinente e que tem ganhado mais destaque, o do próprio Habermas, que arrasa essa concepção moderna burguesa delimitando que:

O atual significado da expressão "sociedade civil" não coincide com o da
"sociedade burguesa", da tradição liberal, que Hegel chegara a tematizar
como "sistema das necessidades", isto é, como sistema do trabalho social e
do comércio de mercadorias numa economia de mercado. Hoje em dia, o
termo "sociedade civil" não inclui mais a economia constituída através do
direito privado e dirigida através do trabalho, do capital e dos mercados de
bens, corno ainda acontecia na época de Marx e do marxismo. O seu
núcleo institucional é formado por associações e organizações livres, não
estatais e não econômicas, as quais ancoram as estruturas de comunicação
da esfera pública nos componentes sociais do mundo da vida. A sociedade
civil compõe-se de movimentos, organizações e associações, os quais
captam os ecos dos problemas sociais que ressoam nas esferas privadas,
condensam-nos e os transmitem, a seguir, para a esfera pública política. O
núcleo da sociedade civil forma urna espécie de associação que
institucionaliza os discursos capazes de solucionar problemas,
transformando-os em questões de interesse geral no quadro de esferas
públicas. Esses "designs" discursivos refletem, em suas formas de
organização, abertas e igualitárias, certas características que compõem o
tipo de comunicação em torno da qual se cristalizam, conferindo-lhe
continuidade e duração.

Somente a sociedade civil organizada, longe das influências diretas do Estado e do Mercado, é capaz de empoderar-se para tomar frente ao seu papel social. Empoderar-se não é nada mais que vislumbrar a efetiva busca da cidadania ativa e do exercício de luta pelos interesses comuns democráticos e humanos dos cidadãos.

O tema do empoderamento social não é novo, tem suas raízes, como preleciona Herriger ${ }^{34}$, por volta do século XVI com a Reforma Protestante. 0 sentimento popular que emergia era contrário ao insustentável autoritarismo da Igreja Católica com seu viés político e religioso destoado dos anseios de justiça social, o que acabou por fulminar uma postura mais proativa da sociedade.

O marco histórico que trouxe a notoriedade do empoderamento se vislumbrou no século XX, principalmente em decorrência dos movimentos sociais empreendidos nos Estados Unidos da América, como o movimento negro (Black Moviment). 0 empowement começou a ser utilizado como sinônimo de emancipação social, em que a auto-estima dos membros dos grupos sociais era ampliada.

E como dito anteriormente, é em ambientes com maior capital social que podemos vislumbrar uma amplitude de possibilidades de empoderamento social na consecução de ideários favorativos frente aos detentores do poder político e do próprio mercado. É através da organização, do associativismo e da ampliação de 
redes de inter-relação social que as comunidades podem desempenhar melhor seu papel na construção de sua emancipação social.

Nesse sentido podemos citar o professor Ferdinand Cavalcanti Pereira que nos ensina que

\begin{abstract}
Empoderamento significa em geral a ação coletiva desenvolvida pelos indivíduos quando participam de espaços privilegiados de decisões, de consciência social dos direitos sociais. Essa consciência ultrapassa a tomada de iniciativa individual de conhecimento e superação de uma situação particular (realidade) em que se encontra, até atingir a compreensão de teias complexas de relações sociais que informam contextos econômicos e políticos mais abrangentes. 0 empoderamento possibilita tanto a aquisição da emancipação individual, quanto a consciência coletiva necessária para a superação da "dependência social e dominação política". Enfim, superação da condição de desempoderamento das populações pobres, as quais, segundo Nyerere (1979), não podem se desenvolver se não tiverem poder. ${ }^{35}$
\end{abstract}

Não se procura mais a manutenção do status quo ante, mas a participação efetiva dos atores sociais na construção de maior vínculo associativo no que lhes diz respeito.

Afinal, o viés consensual debatido entre uma associação de pessoas, livres e iguais, repousa na unidade de um processo consentido. Tal processo forma, conforme Habermas, a constituição até mesmo de um Estado de Direito. 'Numa sociedade pluralista, a constituição expressa um consenso formal. Os cidadãos querem regular sua convivência de acordo com princípios que podem encontrar o assentimento fundamentado de todos, por serem do interesse simétrico de todos.,36 E é justamente esse empoderamento o passo fundamental, dentro de um viés democrático e, amparado no acúmulo de capital social, que a sociedade civil pode ensejar o seu papel de protagonista na busca do bem comum, atuando firmemente contra os interesses que possam se mostrar atentatórios aos ditames democráticos e participaticionais do Estado e do Mercado.

\title{
CONCLUSÕES
}

Em uma economia de mercado, pautada sob a égide de um neoliberalismo cada vez mais predatório e mais desumano, tomando pessoas em simples aglomerados consumistas, e, gerando uma infinidade de "sem rostos" espraiados pelas esquinas ao relento e ao frio, é imperioso uma postura firme e forte de repulsa a tal postura.

Em sociedades com menor desenvolvimento de capital social, é notório os velhos problemas que circundam os interesses públicos, tais como o clientelismo, a falta de civismo, a falta de interesse políticos, etc., e, justamente esses problemas que dificultam todo 0 ideário de formação democrática capaz de ensejar a viabilidade prática de maior participação social no trato dos interesses da sociedade.

Mesmo que estejamos sob uma égide democrática, calcada em um viés que permite, como no caso brasileiro, a existência de ambientes democráticos que possibilitem a criação de redes e associativismo, independente do Estado e do 
Mercado, os vícios nas próprias instituições democráticas causam, muitas vezes, a ineficácia dessa possibilidade.

Para existir uma verdadeira postura ativa de uma sociedade civil organizada, é imperioso que os cidadãos, que compõe esse sujeito social que é a própria sociedade civil, entendam a necessidade da formação do capital social e o utilizem para fazer frente aos desmandos do Estado e do próprio Mercado.

\title{
THE NECESSARY OVERRULE OF REPRESENTATIVE MODEL ON THE CONSTRUCTION OF LOCAL SOCIAL POWER
}

\begin{abstract}
The democratic idea embodies the vision of overcoming legalistic or merely representative of social concerns. The filters used by representatives of the people denote some change in social interests, suffering the interference of other social actors, such as the Market Economic, the real intention and direction of popular will in achieving a democratic state. Therefore, it is imperative to stress the need to overcome the representative view of hermeneutics rather broad denoting the emanation of power by the people themselves, opening up the debate on the creation of public spaces towards the dialogic social interests. These are public spaces that will allow you to create and back-feed the social capital in communities, creating a proper social empowerment, which is the only possible mechanism to make the desire of the people really capable of internalizing the social and public demands.
\end{abstract}

Keywords: City. Representation and Administration Shared. Social capital. Social empowerment.

\section{NOTAS}

1 Professor do Programa de Pós-Graduação em Direito, Mestrado - da Universidade de Santa Cruz do Sul - UNISC, e Doutor pela Universidade do Vale do Rio dos Sinos com estágio de doutoramento pela Universidade de Lisboa. Coordenador da Pós-Graduação em Direito Municipal UNISC/ESDM e Coordenador do subgrupo de estudos Gestão Local e Políticas Públicas, do grupo Estado, Administração Pública e Sociedade (CNPq). E-mail: hermany@unisc.br

2 Advogado, Mestrando em Direito na Universidade de Santa Cruz do Sul. Membro do sub-grupo de Estudos Possibilidades e Perspectivas de Consolidação do Princípio Federativo a partir do Paradigma da governança Local, do Grupo Estado, Administração Pública e sociedade (CNPQ).

3 Cf. VIEIRA, Lizst. Cidadania e globalização. Rio de Janeiro: Record, 2004, p. 45.

4 Expõe Bobbio que "A assembléia dos cidadãos - a democracia que Rousseau tinha em mente - é um instituto, como de resto Rousseau sabia muito bem, que pode ter vida apenas numa pequena comunidade, como era a do modelo clássico por excelência, a Atenas do V e do IV séculos, quando os cidadãos não passavam de poucos milhares e a sua assembléia, considerando-se os ausentes por motivo de força maior ou por livre e espontânea vontade, reunia-se com todos juntos no lugar estabelecido (no qual, escreve Glotz, raramente podiam ser 
vistos mais que dois ou três mil cidadãos, mesmo que na colina onde habitualmente se realizavam as assembléias ordinárias pudessem estar, sempre segundo Glotz, vinte e cinco mil pessoas em pé e dezoito mil sentadas)." BOBBIO, Norberto. O futuro da democracia; uma defesa das regras do jogo. Rio de Janeiro: Paz e Terra, 1986, p. 53. ROUSSEAU, Jean-Jacques. $O$ contrato social: princípios de direito político. Rio de Janeiro: Ed. de Ouro, 1996, p. 22.

6 ROUSSEAU, op. cit., p. 108.

7 PATEMAN, Carole. Participação e teoria democrática. Rio de Janeiro: Paz e Terra, 1992, p. 35.

8 ROUSSEAU, op. cit., p. 35.

9 BOBBIO, Norberto. O futuro da democracia; uma defesa das regras do jogo. Rio de Janeiro: Paz e Terra, 1986, p. 41

Ibidem, p. 44

11 SCHUMPETER, Joseph Alois. Capitalismo, socialismo e democracia. Rio de Janeiro: Fundo de Cultura, 1961, p. 295.

12 Ibidem, p. 42.

13 SCHUMPETER, op. cit., p. 296.

14 Mesmo não se referindo diretamente ao exposto no presente ensaio; sobre o tema do nazismo se recomenda a leitura do livro Modernidade e Holocausto de Zygmunt Bauman, para o entendimento das relações de poder e da produção de uma indiferença moral do povo em função de um ideário autoritário e apregoador do racismo e da superioridade de uma raça em detrimento das demais.

PATEMAN, Carole. Participação e teoria democrática. Rio de Janeiro: Paz e Terra, 1992, p. 13. PATEMAN, op. cit., p. 40.

Bem lembra Lizst Vieira ao delimitar que: '[...] a existência de espaços públicos independentes das instituições do governo, do sistema partidário e das estruturas do Estado é condição necessária da democracia contemporânea. Como intermediações entre o nível do poder político e as redes da vida cotidiana, esses espaços públicos requerem simultaneamente os mecanismos da representação e da participação. Ambos são fundamentais para a existência da democracia nas sociedades complexas. Os espaços públicos são pontos de conexão entre as funções de governo e a representação de conflitos.". VIEIRA, Lizst. Cidadania e globalização. Rio de Janeiro: Record, 2004.

RODRIGUES, Adriano Vasco. Economia Social: aprender a cooperar. Instituto António Sérgio do Sector Cooperativo - INSCOOP. Pensamento Cooperativo. O Terceiro Sector em Portugal, Revista de Estudos Cooperativos, n. 2, Lisboa, 2001, p. 49.

SCHMIDT, João Pedro. Capital Social e políticas públicas. In: LEAL, Rogério Gesta. (Org.) Direitos sociais e politicas públicas: desafios contemporâneos. Santa Cruz do Sul: EDUNISC, 2003, p. 422.

21 ALTHUSSER, Louis. Aparelhos ideológicos de estado: nota sobre os aparelhos ideológicos de Estado. 4. ed. Rio de Janeiro: Graal, 1989, p. 63.

22 HANIFAN, Lyda Johnson. The rural school community center. In: Annals of the American Academy of Political and Social Science, $\mathrm{n}^{\circ} .67,1916$. COLEMAN, J. S. "Social Capital in the Creation of Human Capital" in LESSER, L. L. Knowledge and Social Capital: Foundations and Applications. Boston, Butterworth Heinemann: 1999, p. 20. PUTNAM, Robert. Making democracy work: civic traditions in modern Italy. 1993. SANTOS JÚNIOR, O. A.; AZEVEDO, S.; QUEIROZ RIBEIRO, L. C. Democracia e gestão local: a experiência dos conselhos municipais no Brasil. In: Governança democrática e poder local: a experiência dos conselhos municipais no Brasil. Rio de Janeiro: Revan, Fase, 2004, p. 17.

DURSTON, J. 'Capital social: parte del problema, parte de la solución, su papel en la persistencia y en la superación de la pobreza en América Latina y el Caribe" in ATRIA, R. Capital Social y Reduccion de la Pobreza en la América y el Caribe: en busca de un nuevo paradigma. Naciones Unidas, Santiago de Chile, 2003.

28 LEAL, Rogério Gesta. Os pressupostos epistemológicos e filosóficos da gestão de políticas públicas no estado democrático de direito. In: Direitos sociais e políticas públicas: desafios contemporâneos. Santa Cruz do Sul: EDUNISC, 2003, p. 857.

29 HABERMAS, Jürgen. Direito e democracia: entre facticidade e validade. Volume I. Tradução Flávio Beno Siebeneichler. Rio de Janeiro: Tempo Brasileiro, 1997, p. 92. 
Nesse sentido ver RENNO, L. R. 'Estruturas de oportunidade política e Engajamento em Organizações da Sociedade Civil: Um Estudo Comparado sobre a América Latina", Revista de Sociologia Política, n. 21, nov. 2003.

Nesse sentido ver: HOBBES, Thomas. Leviatã ou matéria, forma e poder de um Estado eclesiástico e civil. São Paulo: Ícone, 2000; ROUSSEAU, Jean-Jacques. Discurso sobre a origem $e$ os fundamentos da desigualdade entre os homens. 3. ed. São Paulo: Martins Fontes, 2005; LOCKE, John. Segundo tratado sobre o govermo civil e outros escritos: ensaio sobre a origem, os limites e os fins verdadeiros do governo civil. Petrópolis: Vozes, 1994; ROUSSEAU, Jean-Jacques. Discurso sobre a origem e os fundamentos da desigualdade entre os homens. 3. ed. São Paulo: Martins Fontes, 2005, p. 203.

33 HABERMAS, Jürgen. Direito e democracia: entre facticidade e validade. Volume II. Tradução Flávio Beno Siebeneichler. Rio de Janeiro: Tempo Brasileiro, 1997, p. 99.

FERDINAND, Cavalcanti Pereira. $O$ que é empoderamento? Disponível em http://www.fapepi.pi.gov.br/novafapepi/sapiencia8/artigos1.php. <acesso em 10 de Jun, 2009> HABERMAS, op. cit., p. 584.

\section{REFERÊNCIAS}

ALTHUSSER, Louis. Aparelhos ideológicos de estado: nota sobre os aparelhos ideológicos de Estado. 4. ed. Rio de Janeiro: Graal, 1989.

ARAÚJO, Maria Celina Soares D'. Capital Social. Rio de Janeiro: Jorge Zahar, 2003.

BOBBIO, Norberto. $O$ futuro da democracia: uma defesa das regras do jogo. Rio de Janeiro: Paz e Terra, 1986.

COLEMAN, J. S. "Social Capital in the Creation of Human Capital" in LESSER, L. L. Knowledge and Social Capital: Foundations and Applications. Boston, Butterworth Heinemann: 1999.

DURSTON, J. 'Capital social: parte del problema, parte de la solución, su papel en la persistencia y en la superación de la pobreza en América Latina y el Caribe" in ATRIA, R. Capital Social y Reduccion de la Pobreza en la América y el Caribe: en busca de un nuevo paradigma. Naciones Unidas, Santiago de Chile, 2003.

FERDINAND, Cavalcanti Pereira. $O$ que é empoderamento? Disponível em http://www.fapepi.pi.gov.br/novafapepi/sapiencia8/artigos1.php. <acesso em 10 de Jun, 2009>.

FUKUYAMA, Francis. Confiança: As virtudes sociais e a criação da prosperidade. Rio de Janeiro, Rocco, 1996.

HABERMAS, Jürgen. Direito e democracia: entre facticidade e validade. Volume I. Tradução: Flávio Beno Siebeneichler. Rio de Janeiro: Tempo Brasileiro, 1997.

. Direito e democracia: entre facticidade e validade. Volume II. Tradução: Flávio Beno Siebeneichler. Rio de Janeiro: Tempo Brasileiro, 1997. 
HANIFAN, Lyda Johnson. The rural school community center. In: Annals of the American Academy of Political and Social Science, $n^{\circ}$. 67, 1916.

HERRIGER, N. Empowerment in der sozialen arbeit. Stuttgart: Eine Einfuhrung, 1997.

HOBBES, Thomas. Leviatã ou matéria, forma e poder de um Estado eclesiástico e civil. São Paulo: Ícone, 2000.

LEAL, Rogério Gesta. Os pressupostos epistemológicos e filosóficos da gestão de políticas públicas no estado democrático de direito. In: - Direitos sociais e políticas públicas: desafios contemporâneos. Santa Cruz do Sul: EDUNISC, 2003.

LOCKE, John. Segundo tratado sobre o governo civil e outros escritos: ensaio sobre a origem, os limites e os fins verdadeiros do governo civil. Petrópolis: Vozes, 1994.

PATEMAN, Carole. Participação e teoria democrática. Rio de Janeiro: Paz e Terra, 1992.

PUTNAM, Robert. Making democracy work: civic traditions in modern Italy, EDITORA. 1993.

RENNO, L. R. 'Estruturas de oportunidade política e Engajamento em Organizações da Sociedade Civil: Um Estudo Comparado sobre a América Latina" in Revista de Sociologia Política, n. 21, nov. 2003.

RODRIGUES, Adriano Vasco. Economia Social: aprender a cooperar. Instituto António Sérgio do Sector Cooperativo - INSCOOP. Pensamento Cooperativo. 0 Terceiro Sector em Portugal. Revista de Estudos Cooperativos, n. 2, Lisboa, 2001.

ROUSSEAU, Jean-Jacques. Discurso sobre a origem $e$ os fundamentos da desigualdade entre os homens. 3. ed. São Paulo: Martins Fontes, 2005;

$\overline{\text { Ouro, } 1996 .}$

O contrato social: princípios de direito político. Rio de Janeiro: Ed. de

SANTOS JÚNIOR, O. A.; AZEVEDO, S.; QUEIROZ RIBEIRO, L. C. Democracia e gestão local: a experiência dos conselhos municipais no Brasil. In: Governança democrática e poder local: a experiência dos conselhos municipais no Brasil. Rio de Janeiro: Revan, Fase, 2004.

SCHMIDT, João Pedro. Capital Social e Políticas Públicas. In: LEAL, Rogério Gesta. (Org.). Direitos sociais e políticas públicas: desafios contemporâneos. Santa Cruz do Sul: EDUNISC, 2003.

SCHUMPETER, Joseph Alois. Capitalismo, socialismo e democracia. Rio de Janeiro: Fundo de Cultura, 1961.

VIEIRA, Lizst. Cidadania e globalização. Rio de Janeiro: Record, 2004. 
Recebido para publicação 09/11/2009

Aceito para publicação 27/12/2009 